\title{
Pengaruh ekstrak goldenfish pada umpan bubu dasar terhadap hasil tangkapan ikan-ikan karang
}

\author{
The effect of goldenfish extract injected to baits of bottom trap on the catch of coral fishes
}

JOANDI C. ARENDEGE*, EMIL REPPIE dan IVOR L. LABARO

Program Studi Pemanfaatan Sumberdaya Perikanan, Fakultas Perikanan dan Ilmu Kelautan, Universitas Sam Ratulangi, Manado 95115

\begin{abstract}
Bottom traps have been used widely by coastal communities in North Sulawesi to catch coral fishes, since it is simple in design, cheaper and easy to manage with a small boat. The catching success of a baited fishing gear is based on the most fundamental activities of an animal's life - searching for and capturing food. Addition of goldenfish extract to the bait could increase the fishing power of bottom trap. But scientific information about its applications is not available yet. Therefore, the objective of this research was to study the effect of goldenfish extract oil added to bait of bottom trap on the capture of coral fishes; and to identify the catch. This research was done in coastal waters of Bira village, Tabukan Tengah District of Sangihe Islands Regency; based on experimental method. Six units of bamboo traps were operated in nine trips; where tree units of them used scad mackerel bait that injected with goldenfish extract, and tree other units just used scad mackerel bait without goldenfish extract; and the capture data were analyzed using a t test. The catch traps during the study was 176 fish; where 124 fish was caught by scad mackerel bait with goldenfish extract; and 52 fish was caught by bait without extract. Analysis of t test show that the addition of goldenfish extract to the bait could increase the catch of bottom trap.
\end{abstract}

Keywords: bottom trap, goldenfish extract, baits, coral fishes

\begin{abstract}
ABSTRAK
Bubu dasar merupakan salah satu alat tangkap yang umum digunakan oleh masyarakat nelayan untuk menangkap ikan-ikan karang, karena konstruksinya sederhana, relatif murah dan mudah dioperasikan dengan kapal atau perahu ukuran kecil. Keberhasilan alat tangkap berumpan sangat ditentukan oleh aktivitas hidup ikan dalam hal mencari dan menangkap makanan. Pemberian ekstrak goldenfish pada umpan, diduga dapat meningkatkan kemampuan tangkap dari bubu dasar. Namun informasi ilmiah seperti ini belum banyak tersedia. Oleh karena itu, penelitian ini bertujuan untuk mempelajari pengaruh pemberian ekstrak goldenfish pada umpan bubu terhadap hasil tangkapan ikan-ikan karang; dan mengidentifikasi jenis-jenis ikan yang tertangkap. Penelitian ini dikerjakan di perairan pantai Kampung Bira, Kecamatan Tabukan Tengah, Kapupaten Kepulauan Sangihe; didasarkan pada metode eksperimental. Enam unit bubu bambu dioperasikan selama sembilan trip untuk mengumpulkan data; dimana tiga unit menggunakan umpan malalugis yang disuntikan dengan ekstrak goldenfish; dan tiga unit lainnya menggunakan umpan malalugis tanpa ekstrak goldenfish; dan data tangkapan dinalisis dengan uji t. Hasil tangkapan bubu selama penelitian berjumlah 176 ekor, sebanyak124 ekor tertangkap dengan umpan berekstrak dan 52 ekor tertangkap dengan umpan bubu tanpa ekstrak. Analisis uji t menunjukkan bahwa bahwa penggunaan umpan berekstrak pada bubu memberikan hasil tangkapan yang nyata lebih baik dibandingkan dengan umpan tanpa ekstrak pada bubu.
\end{abstract}

Kata-kata kunci: bubu dasar, ekstrak goldenfish, umpan, ikan karang

\section{PENDAHULUAN}

Bubu dasar merupakan salah satu alat tangkap yang umum digunakan oleh masyarakat nelayan

\footnotetext{
* Penulis untuk penyuratan; email: juandyarendege@gmail.com
}

untuk menangkap ikan-ikan karang, karena konstruksinya sederhana, relatif murah dan mudah dioperasikan dengan kapal atau perahu ukuran kecil. Sayangnya, praktek pengoperasian bubu tradisional biasanya bersifat merusak, di mana nelayan menutup alat tangkap dengan patahan 
karang hidup untuk menarik ikan target. Walaupun alat tangkap ini telah berkembang sejak lama, tetapi efisiensi penangkapan ikan dan selektivitasnya masih memiliki potensi pengembangan untuk memenuhi kriteria ramah lingkungan dan berkelanjutan (Reppie, 2010).

Keberhasilan alat tangkap berumpan sangat ditentukan oleh aktivitas hidup ikan dalam hal mencari dan menangkap makanan. Pengetahuan yang diperoleh melalui studi-studi tentang tingkah laku ikan mengambil makanan akan sangat membantu untuk memahami interaksi spesies target dengan alat tangkap berumpan (Lokkeborg, 1994).

Fokus utama untuk memahami proses tertangkapnya ikan adalah tertuju pada umpan dan bagaimana komposisi kimianya yang merangsang ikan untuk makan; kemudian penglihatan dan penampilan fisik yang dapat menstimulasi respon positif atau negatif terhadap alat tangkap (Reppie, 2010). Pemberian ekstrak goldenfish pada umpan diduga dapat meningkatkan kemampuan tangkap dari alat bubu dasar. Namun informasi ilmiah seperti ini belum banyak tersedia. Oleh karena itu, penelitian ini bertujuan untuk mempelajari pengaruh pemberian ekstrak goldenfish pada umpan bubu terhadap hasil tangkapan ikan-ikan karang; dan mengidentifikasi jenis-jenis ikan yang tertangkap.

\section{METODE PENELITIAN}

Penelitian ini dilaksanakan di perairan Kampung Bira Kecamatan Tabukan Tengah Kabupaten Kepulauan Sangihe pada bulan Februari-April 2015, dengan mengikuti metode eksperimental yaitu suatu rancangan percobaan yang diujicobakan untuk memperoleh informasi tentang persoalan yang sedang diteliti. Melalui metode ini dapat diperoleh informasi yang diperlukan dalam melakukan penelitian tentang persoalan yang akan dibahas sehingga akan dihasilkan suatu kesimpulan sesuai dengan tujuan penelitian (Sudjana, 1994).

Teknik pengumpulan data dilakukan dengan mengoperasikan enam unit alat tangkap bubu bambu. Tiga unit bubu menggunakan umpan malalugis (Decapterus macarellus) yang disuntikkan ekstrak goldenfish; sedangkan tiga unit bubu lainnya menggunakan umpan malalugis tanpa ekstrak goldenfish; yang dioperasikan secara bersamaan selama sembilan trip. Pelepasan atau penurunan alat tangkap yang telah berumpan ditempatkan di dasar perairan dan dibiarkan semalam kemudian diangkat pada esok paginya.

Hasil tangkapan pada setiap pengamatan dicatat, diidentifikasi, berdasarkan pada masingmasing perlakuan dan trip operasi. Data tangkapan dianalisis dengan $T_{0}$ dihitung dengan mengunakan analisis komparatif dua sampel berkorelasi (Soepeno, 2002), dengan rumusan sebagai berikut:

$$
t=\frac{\bar{X}-\bar{Y}}{\sqrt{\frac{\sum D^{2}-\frac{\left(\sum D\right)^{2}}{n}}{(n-1)}}}
$$

di mana:

$\bar{X}=$ Jumlah rata-rata hasil tangkapan bubu yang menggunakan umpan berekstrak

$\bar{Y}=$ Jumlah rata-rata hasil tangkapan bubu yang menggunakan umpan tanpa ekstrak

$\mathrm{D}=\mathrm{X}-\mathrm{Y}$

$n=$ Jumlah trip operasi penangkapan

\section{HASIL DAN PEMBAHASAN}

\section{Hasil tangkapan}

Hasil tangkapan bubu selama penelitian berjumlah 176 ekor, sebanyak 124 ekor tertangkap dengan umpan berekstrak dan 52 ekor tertangkap dengan umpan bubu tanpa ekstrak (Tabel 1). Jenis-jenis ikan yang tertangkap terdiri dari 35 spesies (Tabel 2).

\section{Hasil analisis}

Untuk kepentingan analisis uji t, maka data dalam Tabel 1 disederhanakan dan diolah lebih lanjut menjadi seperti Tabel 3. Hasil analisis menunjukan bahwa $\mathrm{t}$ hitung $=3,266^{>} \mathrm{t}$ tabel ${ }_{0,05 ; 8}=2,306$; sehingga menolak $\mathrm{H}_{0}$ dan menerima $\mathrm{H}_{1}$, dimana hal ini menjelasan bahwa penggunaan umpan berekstrak pada bubu, memberikan hasil tangkapan yang berbeda nyata dibandingkan dengan umpan tanpa ekstrak pada bubu.

\section{Kisaran panjang total ikan}

Jenis-jenis ikan yang dideskripsikan kisaran panjangnya adalah hasil tangkapan yang dominan, yaitu Balistapus undulatus, Siganus spinus, Ctenochaetus striatus, Lutjanus gibbus dan Ctenochaetus binotatus 
J.C. Arendege dkk.

Tabel 1. Hasil tangkapan bubu menurut perlakuan

\begin{tabular}{ccccccccc}
\hline Trip & \multicolumn{8}{c}{ PERLAKUAN UMPAN } \\
\cline { 2 - 8 } operasi & \multicolumn{7}{c}{ Umpan berekstrak } & \multicolumn{7}{c}{ Umpan tanpa ekstrak } \\
\cline { 2 - 8 } & 1 & 2 & 3 & T & 1 & 2 & 3 & T \\
\hline 1 & 12 & 5 & 5 & 22 & 3 & 3 & 2 & 8 \\
2 & 5 & 4 & 4 & 13 & 2 & 2 & 1 & 5 \\
3 & 3 & 3 & 5 & 11 & 2 & 1 & 2 & 5 \\
4 & 4 & 5 & 6 & 15 & 3 & 2 & 1 & 6 \\
5 & 4 & 3 & 5 & 12 & 2 & 2 & 1 & 5 \\
6 & 5 & 4 & 4 & 13 & 2 & 2 & 2 & 6 \\
7 & 5 & 5 & 5 & 15 & 1 & 2 & 4 & 7 \\
8 & 3 & 4 & 4 & 11 & 2 & 1 & 2 & 5 \\
9 & 4 & 4 & 4 & 12 & 1 & 2 & 2 & 5 \\
\hline Jumlah & 45 & 37 & 42 & 124 & 18 & 17 & 17 & 52 \\
\hline
\end{tabular}

Tabel 2. Jenis-jenis ikan yang tertangkap

\begin{tabular}{|c|c|c|c|c|}
\hline \multirow{2}{*}{ No } & \multicolumn{3}{|l|}{ Jenis ikan } & \multirow{2}{*}{$\begin{array}{l}\text { Jumlah } \\
\text { (ekor) }\end{array}$} \\
\hline & Nama Ilmiah $(*)$ & Nama Indonesia & Nama Lokal & \\
\hline 1 & Balistapus undulatus & Ikan Kambing & Sunga & 33 \\
\hline 2 & Siganus spinus & Baronang & Kesohe & 23 \\
\hline 3 & Ctenochaetus striatus & Madah & Sembele & 18 \\
\hline 4 & Lutjanus gibbus & Jenaha & Dendapa & 12 \\
\hline 5 & Ctenochaetus binotatus & Madah & Sembele & 9 \\
\hline 6 & Calotomus carolinus & Lembain & Mohongkupa & 8 \\
\hline 7 & Acanthurus pyroferus & Lodem & Sembele & 3 \\
\hline 8 & Acanthurus tennentii & Lodem & Sembele & 7 \\
\hline 9 & Lethrinus harak & Lencam & Menanung & 7 \\
\hline 10 & Acanturus triostegus & Lodem & Darehe & 1 \\
\hline 11 & Acanthurus bariene & Lodem & Sembele & 1 \\
\hline 12 & Chaetodon kleinii & Kepe-Kepe & Kariwembang & 5 \\
\hline 13 & Naso lituratus & Kumai & Toleasi & 5 \\
\hline 14 & Zanclus cornutus & Ikan Hias & Lahebuang & 5 \\
\hline 15 & Cheilinus trilobatus & Bayeman & Dedapele & 4 \\
\hline 16 & Anampses caeruleopunctatus & Keling batik & Bewehang & 3 \\
\hline 17 & Lethrinus xanthochilus & Ketambak & Menanung & 3 \\
\hline 18 & Novaculichthys taeniurus & Pelo & Kakekurang & 3 \\
\hline 19 & Prionurus chrysurus & Kapasan & Kararengise & 3 \\
\hline 20 & Sargocentron praslin & Rengginan & Memeha & 3 \\
\hline 21 & Acanthurus nigrofuscus & Lodem & Sembele & 2 \\
\hline 22 & Amanses scopas & Ikan Kambing & Sunga Kaweweni & 2 \\
\hline 23 & Diodon liturosus & Buntal Karang & Tahentungang & 2 \\
\hline 24 & Myripristis chryseres & Rengginan & Memeha & 2 \\
\hline 25 & Scarus flavipectoralis & Lembain & Elong & 2 \\
\hline 26 & Chaetodon citrinellus & Kepe-kepe & Kariwenbang & 1 \\
\hline 27 & Epinephelus faveatus & Kerapu & Kuhapu & 1 \\
\hline 28 & Halichoeres scapularis & Pelo & Tumbakoe & 1 \\
\hline 29 & Lathrinus atkinsoni & Ketambak & Menanung & 1 \\
\hline 30 & Lethirinus ornatus & Jangki & Menanung & 1 \\
\hline 31 & Mulloidichthys flavolineatus & Biji Nangka & Tio & 1 \\
\hline 32 & Parupeneus bifasciatus & Biji Nangka & Tio & 1 \\
\hline 33 & Parupeneus barberinus & Biji Nangka & Tio & 1 \\
\hline 34 & Siganus fuscescens & Baronang & Bete & 1 \\
\hline 35 & Variola louti & Kerapu & Goropa & 1 \\
\hline \multicolumn{2}{|c|}{ Jumlah } & & & 176 \\
\hline
\end{tabular}


Tabel 3. Analisis perbandingan nilai tengah contoh pengamatan terhadap hasil tangkapan bubu

\begin{tabular}{ccccc}
\hline Trip & $\begin{array}{c}\text { Umpan berekstrak } \\
(\mathrm{X})\end{array}$ & $\begin{array}{c}\text { Umpan tanpa ekstrak } \\
(\mathrm{Y})\end{array}$ & $\mathrm{D}(\mathrm{X}-\mathrm{Y})$ & $\mathrm{D}^{2}$ \\
\hline 1 & 22 & 8 & 14 & 196 \\
2 & 13 & 5 & 8 & 64 \\
3 & 11 & 5 & 6 & 36 \\
4 & 15 & 6 & 9 & 81 \\
5 & 12 & 5 & 7 & 49 \\
6 & 13 & 6 & 7 & 49 \\
7 & 15 & 7 & 8 & 64 \\
8 & 11 & 5 & 6 & 36 \\
9 & 12 & 5 & 7 & 49 \\
\hline Total & 124 & 52 & 72 & 624 \\
\hline Rataan & 13.78 & 5.78 & & \\
\hline $\bar{X}=13,78 ; \bar{Y}=5,78 ;(\Sigma \mathrm{D})^{2}=72^{2}=5184 ; \Sigma \mathrm{D}^{2}=624 ; \bar{X}-\bar{Y}=8,0$ &
\end{tabular}

$X=13,78 ; \quad Y=5,78 ;(\Sigma \mathrm{D})^{2}=72^{2}=5184 ; \Sigma \mathrm{D}^{2}=624 ; \bar{X}-\bar{Y}=8,0$

Taraf nyata $(\alpha)=5 \%(0,05)$ dan $1 \%(0,01)$

Nilai t tabel dengan derajat bebas $(\mathrm{db})=\mathrm{n}-1=8$.

Tabel 4. Kisaran panjang total ikan dominan

\begin{tabular}{|c|c|c|c|}
\hline \multirow{2}{*}{ Jenis ikan } & \multicolumn{2}{|r|}{ Ukuran panjang } & \multirow{2}{*}{$\begin{array}{l}\text { Jumlah } \\
\text { (ekor) }\end{array}$} \\
\hline & No & $(\mathrm{cm})$ & \\
\hline \multirow[t]{5}{*}{ Balistapus undulatus } & 1 & $12-<14$ & 3 \\
\hline & 2 & $14-<16$ & 7 \\
\hline & 3 & $16-<18$ & 11 \\
\hline & 4 & $18-<20$ & 9 \\
\hline & 5 & $\geq 20$ & 3 \\
\hline \multirow[t]{5}{*}{ Siganus spinus } & 1 & $<14$ & 1 \\
\hline & 2 & $14-<16$ & 7 \\
\hline & 3 & $16-<18$ & 9 \\
\hline & 4 & $18-<20$ & 2 \\
\hline & 5 & $\geq 20$ & 4 \\
\hline \multirow{4}{*}{ Ctenochaetus striatus } & 1 & $15-<16$ & 7 \\
\hline & 2 & $16-<17$ & 7 \\
\hline & 3 & $17-<18$ & 2 \\
\hline & 4 & $\geq 18$ & 2 \\
\hline \multirow[t]{4}{*}{ Lutjanus gibbus } & 1 & $17-<18$ & 5 \\
\hline & 2 & $18-<19$ & 4 \\
\hline & 3 & $19-<20$ & 1 \\
\hline & 4 & $20-21$ & 2 \\
\hline \multirow{5}{*}{ Ctenochaetus binotatus } & 1 & $14-<15$ & 1 \\
\hline & 2 & $15-<16$ & 0 \\
\hline & 3 & $16-<17$ & 0 \\
\hline & 4 & $17-<18$ & 2 \\
\hline & 5 & $18-19$ & 6 \\
\hline
\end{tabular}




\section{Pembahasan}

Penambahan ekstrak goldenfish pada umpan bubu memberikan hasil tangkapan yang lebih banyak (124 ekor) dibandingkan dengan umpan bubu tanpa ekstrak goldenfish (52 ekor) terhadap hasil tangkapan ikan-ikan karang atau $70.45 \%$ berbanding $29.55 \%$.

Penelitian tentang rangsangan kimiawi telah dilakukan oleh beberapa ahli antara lain Tester, dkk. (1954) dalam Labaro, dkk. (2008), mencoba menarik perhatian ikan dengan menggunakan anise (adas) pada umpan serta subtitusi lain yang berisi jinten, kanfer, minyak kesturi dan fanili sebagai bau-bauan pada perikanan long line. Namun demikian hasil percobaan tersebut belum memuaskan dan belum bisa diterapkan pada perikanan komersial. Kemudian Kuroki (1969) dalam Labaro, dkk. (2008), juga telah melakukan percobaan sejumlah umpan buatan dari nilon yang dicelup ke dalam minyak cumi-cumi dan umpan alami yang telah ditumbuk terlebih dahulu pada perikanan long line. Ternyata hasil yang diperoleh masih belum memuaskan. Jika dibandingkan dengan penelitian ini, maka terdapat kemiripan. Hasil yang diperoleh bisa diterapkan pada perikanan bubu, karena umpan bubu yang menggunakan ekstrak goldenfish menghasilkan tangkapan yang lebih banyak dibandingkan dengan umpan bubu tanpa ekstrak goldenfish; walaupun masih diperlukan penelitian lanjutan untuk meningkatkan fishing power dari alat tangkap bubu.

Hasil tangkapan terdiri dari 35 spesies, tetapi didominasi secara berturut-turut oleh ikan Balistapus undulatus (33 ekor), Siganus spinus (23 ekor), Ctenochaetus striatus (18 ekor), Lutjanus gibbus (12 ekor) dan Ctenochaetus binotatus (9 ekor).

Panjang total maksimum ikan Balistapus undulatus yang tertangkap adalah $19 \mathrm{~cm}$, jauh di bawah panjang yang umum terdapat di perairan yaitu 26,0 cm. Panjang total maksimum ikan Siganus spinus yang tertangkap adalah $21 \mathrm{~cm}$, sedangkan panjang yang umum terdapat di perairan adalah $18,0 \mathrm{~cm}$; dengan demikian sekitar 26.09\% ikan Siganus spinus yang sudah layak tangkap dan $73.91 \%$ belum layak tangkap.
Panjang total maksimum ikan Ctenochaetus striatus yang tertangkap adalah $18 \mathrm{~cm}$, panjang yang umum terdapat di perairan juga $18,0 \mathrm{~cm}$; tetapi hanya $11.11 \%$ yang layak tangkap dan $88.89 \%$ tidak layak tangkap.

Panjang total maksimum ikan Lutjanus gibbus yang tertangkap adalah $21 \mathrm{~cm}$, panjang yang umum terdapat di perairan juga $45,0 \mathrm{~cm}$, sehingga seluruhnya belum layak tangkap. Panjang total maksimum ikan Ctenochaetus binotatus yang tertangkap adalah $22 \mathrm{~cm}$, tetapi tidak diketahui ukuran panjang yang umum terdapat di perairan, sehingga sulit menentukan ukuran yang layak tangkap.

\section{KESIMPULAN}

Penambahan ekstrak goldenfish pada umpan bubu memberikan hasil tangkapan yang lebih banyak (124 ekor) dibandingkan dengan umpan bubu tanpa ekstrak goldenfish (52 ekor), terhadap hasil tangkapan ikan-ikan karang. Hasil tangkapan bubu terdiri dari 35 spesies ikan karang dan didominasi oleh 5 spesies yaitu Balistapus undulatus, Siganus spinus, Ctenochaetus striatus, Lutjanus gibbus dan Ctenochaetus binotatus.

\section{DAFTAR PUSTAKA}

Allan, G. 2000. A Field Guide for Anglers and Divers. Marine Fishes of South-East Asia. Peripus.

Labaro, I.L., E.M. Katiandagho, E. Reppie, dan J. Budiman. 2008. Pengaruh larutan minyak cumi (cisabu) terhadap hasil tangkapan pancing ulur tuna di perairan sekitar Pulau Batang Dua. Prosiding Konferensi Nasional VI, Pengelolaan Sumberdaya Pesisir dan Lautan.

Lokkeborg, S. 1994. Fish behaviour and longlining. Dalam: A. Fernö dan S. Olsen. Marine Fish Behaviour in Capture and Abundance Estimation. Fishing News Books, Oxford.

Reppie, E. 2010. Pengaruh minyak cumi pada umpan bubu dasar terhadap hasil tangkapan ikan-ikan karang. Jurnal Perikanan dan Kelautan Tropis VI(3): 140-143.

Sudjana. 1994. Desain dan Analisis Eksperimen. Edisi III. Tarsito, Bandung.

White, W.T., Dharmadi, R. Faizah, U. Chodrijah, B.I. Prisantoso, J.J. Pogonoski, M. Pukridge, dan S.J.M. Blaber. 2013. Market Fish of Indonesia (Jenis-jenis Ikan di Indonesia). Australian Centre for International Agrikulture Research (ACIAR), Canberra. 